\title{
'Our biggest killer': Multimodal discourse representations of dementia in the British press
}

\author{
Gavin Brookes ${ }^{\mathrm{a}}$ \\ Kevin Harvey ${ }^{\mathrm{a}}$ \\ Neil Chadborn ${ }^{\mathrm{b}}$ \\ Tom Dening ${ }^{\mathrm{b}}$ \\ ${ }^{a}$ School of English, University of Nottingham \\ ${ }^{\mathrm{b}}$ School of Medicine, University of Nottingham
}

\begin{abstract}
A recent (2016) Office for National Statistics report stated that dementia is now 'the leading cause of death' in England and Wales. Ever fixated with the syndrome (an unfailingly newsworthy topic), the British press was quick to respond to the bulletin, consistently headlining that dementia was the nation's 'biggest killer', while (re)formulating other aspects of the report in distorting and emotive metaphorical terms. In this paper we examine how the media, through use of a recurring set of linguistic and visual semiotic tropes, portrayed dementia as an agentive entity, a 'killer', which remorselessly attacks its 'victims'. Such a broadly loaded and sensationalist representation, we argue, not only construed dementia as a direful and pernicious disease, but also, crucially, obscured the personal and social contexts in which the syndrome is understood and experienced (not least by people with dementia themselves). This intensely lurid type of representation not only fails to address the ageist misinformation and common misunderstandings that all too commonly surround dementia, but is also likely to exacerbate the stress and depression frequently experienced by people with dementia and their families.
\end{abstract}

Keywords: dementia, Alzheimer's disease, media, Office for National Statistics, multimodal critical discourse analysis, photography, neuroimaging

\section{Introduction}

In November 2016, the British Office for National Statistics (ONS, 2016) released a press bulletin stating that dementia had now replaced cancer and heart disease as 'the leading cause of death in England and Wales'. Dementia is a syndrome that involves a range of cognitive impairment symptoms, including memory loss, problems with reasoning, perception and communication skills (WHO, 2016). It is a progressive condition, which means that its symptoms are likely to worsen over time, and for which there is presently no cure. Dementia, according to the ONS bulletin, now accounted for ' $11.6 \%$ of all deaths registered in 2015', although aggregate types of cancer and circulatory disease were still said to be the most common cause of mortality ( $27.9 \%$ and $26.2 \%$ of all deaths, respectively). The report also made it clear that the evident rise in recorded dementia mortality was due to deaths that were formerly attributed to other conditions now being exclusively coded as dementia. (Although dementia is associated with reduced life expectancy, when people with dementia die, their death is more likely to be caused by co-occurring conditions such as pneumonia, rather than 
by dementia directly. In fact, pneumonia is the ultimate cause of death in as many as twothirds of people with dementia (Alzheimer's Society, 2017)).

Such epidemiological niceties, however, were often lost on the British press, which consistently (re)formulated the ONS bulletin in overly dramatic and distorting terms, portraying dementia as nothing less than the nation's 'biggest killer', an agentive entity in its own right, while simplifying and obscuring the social and cultural context in which people make sense of, respond to, and actually live with dementia. The press reports also tended to downplay and, in some instances, overlook altogether some of the (less remarkable) reasons for the increase in dementia-related mortality rates - such as the recent introduction of new international rules for coding deaths, global increases in life expectancy and reduced rates of death from other conditions - omissions which, alongside other discursive designs, served to promote a fear-inducing narrative at the expense of the actual far more complex and nuanced epidemiological picture.

It was no great surprise that the British press gave the ONS bulletin so much avid attention. The report fulfilled a number of criteria which made it eminently 'newsworthy', particularly with respect to the reporting of health and illness. For instance, according to Galtung and Ruge's (1965) influential list of news values, it was a recent 'story' that met the requirements of a significant 'threshold' (of the 529,655 deaths registered in 2015, 61,686 (12\%) were apparently dementia-related), and it also evinced 'cultural proximity', that is, it related to mortality rates in England and Wales rather than countries geographically and culturally distant. Moreover, and perhaps most significantly, the content of the bulletin fitted in with the media's longstanding fixation with dementia and its characteristic portrayal of the condition through a techno-scientific and epidemiological lens, a perspective that has tended to frame the syndrome in the matter of medical research and clinical breakthroughs (van Gorp and Vercruysse, 2012), with a particular emphasis on disease prevalence, causation and the development of pharmaceutical cures (Kirkman, 2006). Such a focus invariably presents only one (i.e. medico-scientific) side of dementia, admitting little possibility of living well with the syndrome, while simultaneously invigorating and reinforcing the stigma that surrounds it (Herskovits, 1995). As Petty et al. (2016) observe, the media dementia narrative is one that often draws on discourses of victimhood and suffering, and hence it is not surprising that a lexicon of distress has become the prevailing means through which dementia is viewed in society.

According to the World Health Organisation (WHO, 2016), there are now 47.5 million people worldwide living with dementia, and each year there are 7.7 million new cases. Based on these figures, the total number of people living with the condition globally is, the WHO calculates, projected to rise to 75.6 million in 2030, trebling by 2050 to 135.5 million. The most recent prevalence figures available suggest that there are likely to be around 850,000 people living with dementia in the $\mathrm{UK}$, a figure that is predicted to rise to 1.142 million people by the year 2025 (Alzheimer's Society, 2014a). This apparent increase in the prevalence of dementia has been interpreted and described by many - particularly commentators in the media, as well as politicians and even scientists themselves - in apocalyptic terms: for example, as a 'rising tide', a 'silent tsunami', and a 'ticking time bomb' (Zeilig, 2014): in a word, an irrepressible force of nature that threatens to overcome us all. Yet despite the global increase in dementia prevalence, the apocalyptic scenario is almost certainly overstated. Indeed, recent studies (Matthews et al., 2016) have revealed that prevalence and incidence rates of dementia - at least in the US, UK and certain other European countries - have actually fallen, and hence the dementia 'crisis' might not be quite 
as apocalyptic as all the doom-laden imagery suggests. Such optimistic counter-claims, of course, make for less sensational, doom-mongering and, ultimately, paper-selling headlines.

The epidemiological picture, and consequently the public comprehension of dementia, is further complicated by the fact that in both lay and professional discourse dementia is surrounded by misinformation and misunderstandings (Zeilig, 2014). Conceptually, dementia is a disputed entity. Clinical definitions typically characterise it as a neurodegenerative disease that affects memory, cognition and behaviour (WHO, 2016). In this sense dementia, rather than being a single discrete disease, actually relates to a range of syndromes of which Alzheimer's disease is the most common variant (van Gorp and Vercruysse, 2012; Zeilig, 2015). Ontologically speaking, however, it is no easy task to distinguish mild cognitive decline, which is not uncommon in normal ageing, from the early onset of dementia (Woods, 2011: 207). Accordingly, for this and other conceptual reasons, there is still no general agreement concerning what dementia actually is 'in neurological terms' (Zeilig, 2015: 12). Given its protean nature - that it defies straightforward definition and remains incurable dementia has become a 'modern medical bogeyman' (NHS, 2011), a fear-freighted term encapsulating society's worst terrors' (Zeilig, 2015: 12).

Against this backdrop of fear, stigma and misinformation, we critically examine the way in which the British press reported the findings of the aforementioned Office for National Statistics statistical bulletin, paying particular attention to the recurring discursive-semiotic strategies used by the media to dramatically frame dementia as a dreaded and devastating disease (van Gorp and Vercruysse, 2012). Although it is not our intention to downplay the seriousness of dementia and the profound impact it has on people's lives (both for people with dementia and their families and carers), we aim to show how the media plays a powerful role in shaping public understandings of dementia, tending to perpetuate, instead of responsibly challenge, negative and stigmatising depictions of the syndrome.

\section{A multimodal discourse approach to dementia in the press}

The 2016 ONS story was covered by ten national newspapers in the UK, including broadsheets, tabloids and freesheets, over the course of two days $\left(14^{\text {th }}\right.$ and $15^{\text {th }}$ November, 2016) (see table 1 below). The Daily Mail devoted two separate articles to the story. Our data therefore consists of eleven individual articles, which we accessed through each newspaper's website. Although our aims are not explicitly comparative with regard to publication type or political orientation, we were nevertheless sensitive to any significant similarities or differences in coverage that might arise during analysis.

Table 1. Articles sampled for analysis.

\begin{tabular}{ccc}
\hline Newspaper & Article title & Online publication \\
\hline Daily Mail & $\begin{array}{c}\text { Dementia and Alzheimer's disease are leading } \\
\text { cause of death for first time (1) }\end{array}$ & 14.11 .2016 \\
& $\begin{array}{c}\text { Dementia is now the leading cause of death and } \\
\text { women are the most vulnerable, new statistics } \\
\text { reveal (2) }\end{array}$ & 14.11 .2016 \\
Express & $\begin{array}{c}\text { Dementia and Alzheimer's overtakes heart } \\
\text { disease as our biggest killer }\end{array}$ & 15.11 .2016
\end{tabular}


Guardian Dementia and Alzheimer's leading cause of death

in England and Wales

14.11.2016

$i$

Dementia is now the leading cause of death in England and Wales

Independent

Dementia overtakes heart disease to become leading cause of death in England and Wales

What is dementia, what are the symptoms and how does it kill?

Dementia is now the biggest killer so it must become top medical priority

Dementia becomes Britain's biggest killer

Telegraph

UK's biggest killer is now dementia, so the

The Sun Government MUST put more resources towards fighting it

Times

Dementia kills more than heart disease

15.11 .2016

Most studies of discourse in news and journalism have tended to focus on the linguistic properties of texts in their analyses, with studies of dementia-related news stories being no exception (e.g. Kirkman, 2006; Doyle et al., 2012; Peel, 2014). Consequently, messages communicated through non-linguistic, particularly visual modes, such as images, fonts and layouts, have tended to be either regarded as secondary to the overall communicative output or, worse still, neglected altogether. Yet contemporary news texts are characteristically multimodal in their design, combining language, image, layout, sound and other semiotic modes. For instance, in their semiotic appraisal of newspaper layouts, Kress and van Leeuwen (1998) observe that readers visually scan newspapers before approaching the written text of an article. This 'reading path' (1998: 205) is liable to be structured and influenced by more salient items such as visual images which, no matter how tangential their depictions, often act as pithy encapsulations and exaggerated illustrations of the written articles to which they relate. We take the view that in the design of newspaper articles, nonlinguistic modes such as images do not merely supplement the linguistic content in these types of texts, but actually form an important part of the ideas, values and overall messages that are communicated (Machin, 2013).

Accordingly this study adopts a multimodal approach to Critical Discourse Analysis (CDA). CDA is understood here to be a theoretical perspective that is concerned with the ways that ideology and power are discursively enacted, reproduced and challenged within particular social and political contexts (Fairclough, 1995). Multimodal Critical Discourse Analysis (MCDA) therefore involves documenting the lexical, visual and other semiotic choices made by text creators and interpreting these in terms of how they relate to their contexts of production and consumption, as well as the wider societ(ies) in which they take place (Machin, 2013). MCDA offers a predictive set of tools that allow analyses to progress from merely describing design decisions in aesthetic terms, to examining the communicative choices made in any textual composition in a more systematic and critical way (Machin, 2013). Our analysis of these newspaper texts will focus on the lexical and visual choices relating to two key, recurring areas of multimodal representation: dementia and the people with dementia. It will begin by exploring how dementia is itself represented in the articles, focusing mainly on linguistic choices to this end, before growing increasingly multimodal in 
perspective to consider the representation of people with dementia, which is accomplished through more visual means (including the use of stock photographs and neuroimaging pictures). Following the analysis we will consider what implications these representations might have for people living with dementia (and their families), as well as for public understanding of the syndrome more generally.

\section{Representing dementia: battles and races}

Across the articles in our data, dementia is variously referred to, or lexicalised, as a 'disease' and a 'condition', and more specifically a 'neurological disorder' (all Daily Mail), a 'progressive neurological disease' (Express), a 'brain condition' (Independent and Mirror), a 'progressive disease' (Metro) and a 'terminal disease' (The Sun). This lexical variation occurs not only across different newspapers, but sometimes within the same article. The most striking example of this contradictory and potentially misleading type of representation can be found in the Metro, where dementia is described as a 'progressive disease', yet, within the same article, readers are also informed that dementia is 'not considered to be a disease but a series of symptoms resulting from damage to the brain' (our emphasis). This terminological inconsistency provides evidence of the broader lack of media understanding about what dementia actually is, a confusion partly born out of the fact that the term dementia refers to a range of symptoms that all have different causes (Hughes, 2011), but which is also likely to be perpetuated by press reports of this type, which tend to mix and conflate terminology, including using the terms 'dementia' and 'Alzheimer's disease' interchangeably, or at least without distinction.

The most stable lexicalisation of dementia in our media data resides in the frequent recourse to militaristic or 'violence' metaphors (Demmen et al., 2015). In the majority of the articles, dementia is construed as an actor that kills and inflicts other forms of violence on those who have it (see the examples below).

The new data shows dementia killed more than twice the amount of women than men (Daily Mail (1))

Dementia and Alzheimer's disease overtakes heart disease as our biggest killer (Express)

What is dementia, what are the symptoms and how does it kill?

(Metro)

Dementia is now the biggest killer so it must become top medical priority (Mirror)

BRITAIN'S biggest killer has no known cure

(The Sun)

Dementia becomes Britain's biggest killer

(Telegraph)

Dementia kills more than heart disease

(Times) 
The metaphorical schema of violence features in all but two of the newspapers in our data (Guardian and $i$ ), and is also manifested linguistically in the description of dementia as 'deadly' (Daily Mail (1)), 'claim[ing] lives' (Independent), 'responsible for' deaths (Daily Mail (1), The Sun), 'devastat[ing] lives', and 'inflict[ing]' a death 'toll' (both Mirror). These kinds of violence tropes are afforded particular salience in six of the articles (Express, Metro, Mirror, The Sun, Telegraph, Times), where they appear not just in the bodies of the articles, but also in the headlines. Taking the prominent form of headlines (which, unlike other the textual elements of a newspaper article, are liable to be read by most readers in their entirety), they pithily encapsulate the story (Reah, 2002), emotively provoking readers' responses at the very outset of the main report.

The construal of dementia as a relentless killer and agent of other forms of violence underscores the seeming inevitability of death for people with dementia, while at the same time backgrounding the possibility for individuals to lead - both socially and physically active and fulfilling lives following a dementia diagnosis: in other words, to live well with dementia. Such metaphors of violence, furthermore, encourage us to see people with dementia as victims ravaged by a marauding disease, the press's collective appetite for depredatory tropes here contributing to a fear-inducing, stigmatising understanding of the syndrome. It might reasonably be argued that metaphors provide useful linguistic resources for explaining illnesses to the general public, as they provide more familiar and accessible frames of reference. Although we do not dispute the use of metaphor per se, we do contend that the dementia-as-killer metaphor is at best overly simplistic and at worst perniciously inaccurate, given, as we discussed earlier, that people with dementia are more likely to die because of a co-occurring condition, particularly pneumonia.

Beside the use of metaphor, the dementia-as-death-sentence discourse is re-enforced through further linguistic devices, in particular the selective use of quotations attributed to figures from authoritative bodies, such as Hilary Evans, Chief Executive of Alzheimer's Research $\mathrm{UK}$, who is quoted as stating, '[t]hese figures once again call attention to the uncomfortable reality that currently, no-one survives a diagnosis of dementia' (Daily Mail (1) and (2), Guardian, Telegraph). By referencing the voices of experts in this way, the articles in our data are able to appropriate a more authoritative tone (Runblad, Chilton and Hunter, 2006) to legitimise (van Leeuwen, 2007) the claim that dementia is itself a direct cause of death. As Gwyn (2002: 92) puts it, '[t]raditionally, patients are given the 'facts' by professionals ... Likewise, the conventional construction of professional 'voice' in media stories on health and illness functions as a vital element in the presentation of medical facts as authoritative and legitimized'.

The dementia-as-killer discourse is substantiated and emotively dramatised further through the persistent use of a quantification rhetoric, which frames dementia as responsible for the deaths of large numbers of people. In the representative examples below, dementia is depicted as 'killing' large numbers of people, who are variously presented as a mixture of raw figures, percentages, and fractions.

Of the 529,655 deaths registered in England and Wales in 2015, 11.6\% were attributable to dementia or Alzheimer's, according to the Office for National Statistics. Among those aged 80 or over, dementia and Alzheimer's accounted for $13.7 \%$ of male deaths and $21.2 \%$ of deaths among women. (Daily Mail (1)) 
New figures from the Office for National Statistics (ONS) show that $\mathbf{6 1 , 6 8 6}$ people died of Dementia or Alzheimer's last year, 11.6 per cent of all deaths.

(Express)

Last year, 61,686 (11.6\%) out of a total of 529,655 deaths registered in England and Wales were attributable to dementia (Guardian)

Figures from the Office for National Statistics show that $\mathbf{1 1 . 6}$ per cent of the 529,655 deaths in England and Wales in 2015 were attributable to dementia or Alzheimer's (i)

In 2015, dementia claimed more than $\mathbf{6 1 , 0 0 0}$ lives and accounted for $\mathbf{1 1 . 6}$ per cent of recorded deaths

(Independent)

More than 61,000 people died from dementia, which accounts for $11.6 \%$ of all deaths recorded in England and Wales. (Metro)

Today The Sun calls on the Government and drugs firms to put the maximum resources available into combating dementia, a disease that was responsible for more than 61,000 deaths in the UK last year.

(The Sun)

Dementia and Alzheimer's are now the biggest cause of death in England and Wales after jumping by a fifth in a single year, official figures show. They overtook heart disease as Britain's biggest killer, accounting for almost one in eight deaths recorded in England and Wales 2015 - a total of 61,686 people - according to the Office for National Statistics.

(Telegraph)

Numbers are, as Jones (2013: 40-41) points out, regarded by society as being 'ideologically neutral' and 'immune to human bias', meaning that their use in journalism can enhance the facticity and objectivity of reports. However, Potter et al. (1991) argue that quantification of this type is a far from neutral reflection of reality, but is, rather, a rhetorical device that can be employed strategically to support a particular social, institutional or ideological agenda.

Much like the citation of expert and authoritative voices, the use of quantification rhetoric in the above examples and elsewhere lends credibility to the claim that dementia is itself directly responsible for the deaths described. The use of large numbers in these examples, moreover, helps to foreground and (most likely) exaggerate the scale and impact of dementia, thereby increasing emotional engagement from readers (Seale, 2002: 38), all the while enhancing the story's newsworthiness (Galtung and Ruge, 1965).

Yet, in relation to communication about health and risk, Jones (2013: 40-41) raises a more fundamental concern about the use of numbers, in particular where it is not clear what has been counted, and how. In their review of the dementia prevalence literature, Blume, Persily and Mintzer (1992) reported the tendency for dementia statistics to be calculated in inconsistent ways, including whether or not different types of dementia were taken into 
account. These and other complexities surrounding the calculation of prevalence information about dementia are, however, not mentioned in the articles, but are conveniently obscured, we suggest, so as not to undermine the shock value and fear factor that the media narratives undoubtedly intend to produce. Nowhere is this backgrounding more evident than in the graph below, which features in the Daily Mail (1), Express and Independent.

Figure 1. Graph showing mortality rates for five leading causes of death in England and Wales in 2015, reproduced in Daily Mail (1), Express and Independent

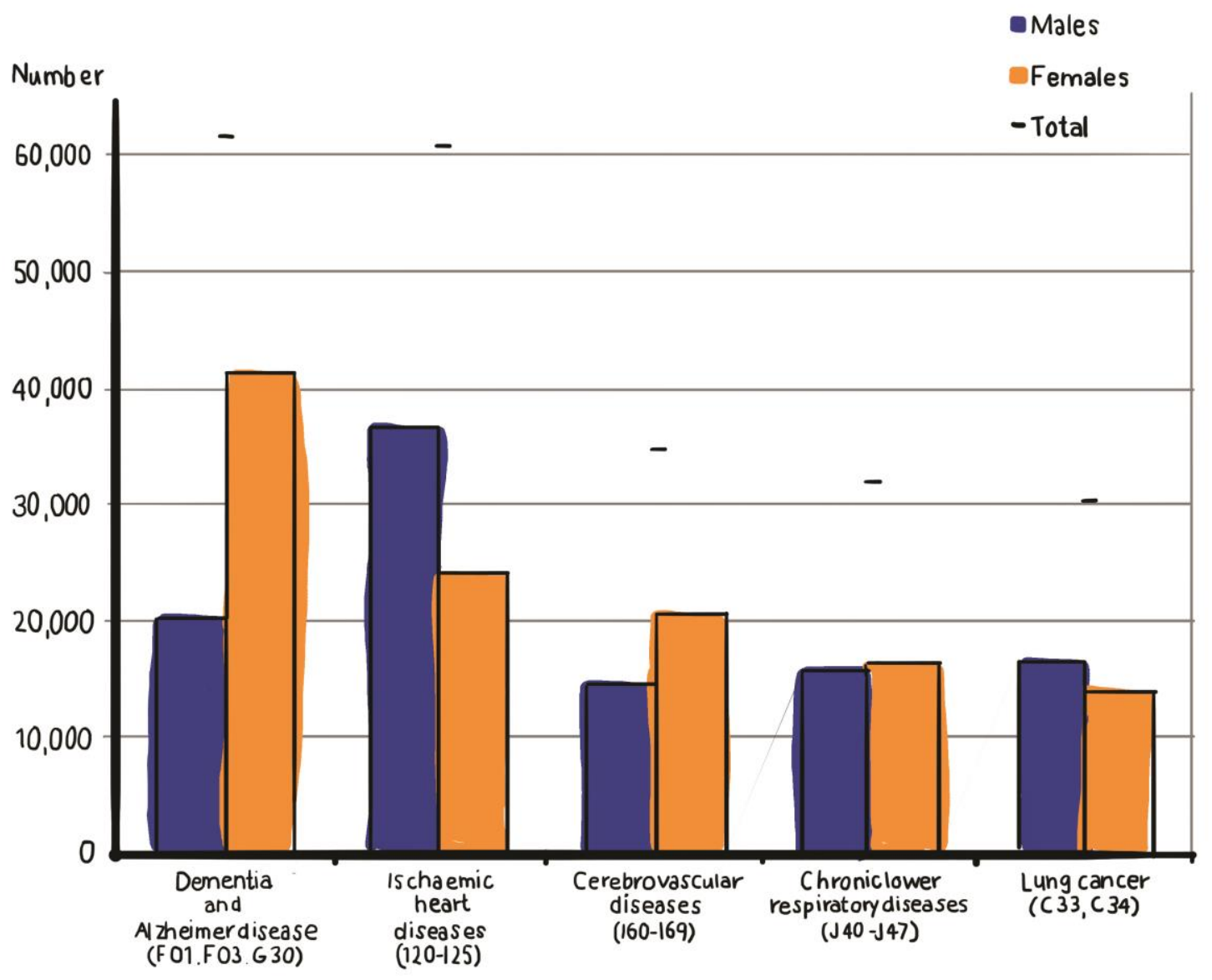

This graph was originally published as part of the ONS report which prompted the articles in our data. It purports to show the number of mortalities associated with the five-leading causes of death in England and Wales in 2015. This graph is reproduced and recontextualised (van Leeuwen and Wodak, 1999) in the three aforementioned articles, taken from one context (scientific bulletin) and appropriated within another (news article). Jones (2013) argues that 'language favours typological meaning-making, the division of phenomena into 'types' (colours, sizes, symptoms, and diseases), whereas visual modes allow for more topological meaning-making in which fine gradations of things like colour, size, swelling, and slope can be expressed' (2013: 54; emphasis in original). As such, the resemiotisation (Iedema, 2003) of the dementia statistics into a graph allows the increase in dementia-related deaths to be presented as glaringly self-evident, inviting reader-viewers to indubitably see and appreciate the reported thanatological trend for themselves (van Dijck, 2006). Furthermore, the use of statistics, graphs, charts and other modes invoke notions of science, knowledge and objectivity. As such, the inclusion of this graph in three of the articles in our data might help 
to authenticate the claim that dementia is, in fact, the leading cause of death in England Wales.

A prominent feature of all of the constructions of dementia explored so far is their consistent focus and emphasis on the direct role of dementia itself in the reported rise in the number of deaths of people with the syndrome. Such a discursive strategy backgrounds, and in many cases elides altogether, the role that factors such as an ageing population and improvements in knowledge and diagnostic tools are likely to have played in the reported increase in dementia diagnoses (for a recent discussion see: Starr, 2017). When these mitigating factors are acknowledged, they tend to be downplayed and framed through a series of low-modality lexical choices that encode a not insignificant degree of doubt:

But the growing mortality rates could be down to doctors having become better at diagnosing the disease (Daily Mail (1))

DEMENTIA and Alzheimer's disease replaced heart disease as the leading cause of death in England and Wales in 2015 - which experts believe is due to an ageing population and better diagnosis of the condition.

(Express)

Deaths among men attributed to dementia also increased last year to 7.9 per cent. This is likely due to longer life expectancy among men, according to the ONS. (Independent)

According to the ONS, dementia overtaking heart disease as the leading cause of due to the ageing population. There is also a suggestion that dementia is now being more effectively diagnosed.

(Metro)

This is partly due to better detection and diagnosis, but the fact remains that in 2016 nobody survives a diagnosis of dementia.'

(The Sun)

The lexical choices emboldened in the above extracts help to downgrade and cast doubt on the influence of the aforementioned mitigating factors on the reported rise in dementia diagnoses, with phrases such as 'could be' (Daily Mail (1)) and 'likely' (Independent) expressing possibility rather than certainty. In a similar vein, these mitigating factors are downgraded in status, from fact to 'belie[f]' (Express) and 'suggestion' (Metro), neither of which is attributed to any particular individual or organisation (unlike the quotations relating to the link between dementia and death explored earlier). In the example taken from The Sun, the role of improved detection and diagnosis is first downgraded to a partial contributor ('partly'), before it is immediately undercut by the clause: 'but the fact remains that in 2016 nobody survives a diagnosis of dementia', ${ }^{1}$ which reinforces the 'fact' that dementia the entity exclusively causes death. The dubious modality that shrouds the above passages is rendered all the more striking when it is compared against the way that the rise in dementia diagnoses and dementia-related deaths are consistently asserted to be 'show[n]' by the new statistics; a transitivity choice which leaves little room for doubt - framed as somehow selfevident and irrefutable. 
In addition to violence and militaristic metaphors, another recurrent trope used to represent dementia in the articles in our data is that of dementia as a competitor that competes against the previous leading cause of death, heart disease, which it actively 'overtake[s]', 'surpasse[s]' and 'knock[s] off' the 'top spot' or the 'top of the table' to become the leading cause of death, or 'biggest killer', as in the examples below:

It [dementia] has knocked heart disease off the top of the table for the first time ever

(Daily Mail (1))

An ageing population and better diagnosis of the condition has led to dementia and Alzheimer's knocking ischaemic heart disease from the top spot, statisticians said. (Daily Mail (2))

Dementia and Alzheimer's disease overtakes heart disease as our biggest killer (Express)

Ageing population and better diagnosis have led to heart disease being knocked off top spot for first time, ONS says

(Guardian)

Figures from the Office for National Statistics show that 11.6 per cent of the 529,655 deaths in England and Wales in 2015 were attributable to dementia or Alzheimer's knocking ischaemic heart disease off the top spot.

(i)

Dementia overtakes heart disease to become leading cause of death in England and Wales

(Independent)

The figures mean that dementia, including Alzheimer's Disease, has now overtaken heart disease as the leading cause of death.

(Metro)

There must be a huge injection of resources to fight dementia now that it has overtaken heart disease as the country's biggest killer.

(Mirror)

With Brits living longer, dementia has now surpassed heart disease as the top cause of death

(The Sun)

Dementia and Alzheimer's have overtaken heart disease as Britain's biggest killer (Telegraph)

Dementia has overtaken heart disease to become the leading cause of death in England and Wales

(Times) 
That dementia is formulated as grammatically agentive in the above passages fits with the violence metaphors we examined earlier, in which dementia was depicted as a malevolent actor that actively and violently pursued its aim of being the 'biggest killer' by devastating the lives of people experiencing the syndrome. As well as competing with other diseases, dementia is also constructed as competing against pharmacological interventions (or, more specifically, government funding of pharmacological interventions), and it is a competition that dementia seems to be 'winning'. The Mirror reports that 'research and treatment have not kept up with the toll inflicted by Alzheimer's and other brain conditions'. Likewise, The Sun reports that 'public spending on dementia trails far behind other terminal illnesses, and drugs companies are loath to invest in curing a disease that won't deliver big profits.' This sporting trope can also be found in a statement by the previously mentioned Hilary Evans, Chief Executive of Alzheimer's Research UK, who is quoted in the Daily Mail (1) and (2), Guardian and Telegraph as warning, '[w]ith the growing numbers of people living with dementia, we urgently need treatments that can stop or slow the diseases that drive this devastating condition'. In fact, so pervasive are the metaphors of violence and sport identified here that Evans actually mixes her metaphors, drawing on the lexis of both domains within the very same press statement: '[d]ementia is not an inevitable part of ageing. It's caused by diseases that can be fought through research, and we must bring all our efforts to bear on what is now our greatest medical challenge.' The government response to dementia is also framed in militaristic terms in the Mirror, which calls for increased resources to 'target' and 'fight' dementia. The newspaper the most committed to this trope is, however, is The Sun, which implores the Government to 'battle', 'fight', 'combat' and 'tackle' dementia, reflects on 'small victories against other previously incurable conditions', and concludes the article with the following call to action: 'This is the biggest medical challenge of our lifetime - we must step up.'

These militaristic frames are conceivably designed to mobilise policy makers to commit massive resources to the development of pharmacological solutions in order to "win" the "battle" against dementia (Annas, 1995). So prominent is this agenda in The Sun in particular that it includes readers in this battle, through its frequent recourse to the inclusive pronouns 'we' and 'our' (Richardson, 2007), for example in the imperative clause: 'we must bring all our efforts to bear on what is now our greatest medical challenge'. This can conceivably be interpreted as an effort by the paper to rouse readers into action - perhaps to put pressure on Government to commit more funding to developing a pharmacological treatment for dementia. Perhaps in an attempt to strengthen its appeal further, The Sun also frames its call for increased funding for developing a pharmacological solution to dementia in a decidedly patriotic rhetoric that is likely designed to appeal to the nationalistic sensibilities of its target readership. Specifically, it suggests that 'we' (i.e. the UK) should be 'proud' that former Prime Minister David Cameron has already pledged millions of pounds of public money to developing a medical cure for dementia. Moreover, Cameron - a protagonist in this story because of this pledge - is pictured in the body of the article, suited and wearing a Remembrance Day poppy - an object (Barthes, 1977: 22-23) that invokes notions of British patriotism, bravery and even warfare (consistent with the broader militaristic metaphorical schema observed earlier). Although this is a recontextualised Press Association stock photograph, likely taken at around the time of Remembrance Day earlier that month, such connotations are transported with it (Machin, 2004), intensifying and raising the stakes of the appeal that the article sets out to make.

The use of militaristic metaphors to frame responses to dementia is problematic for several reasons. Basting argues that the militaristic metaphors used to frame governmental and 
pharmacological responses to dementia cast science as the 'white knight' (Basting, 2009: 39) on which people's hopes of living and surviving with the syndrome depend. Yet such a conception risks over-simplifying the challenge of developing pharmacological interventions, as well as sensationalising their promise in terms of eradicating the impact of illness and disease (Nelkin, 1995). The faith in science that is implicit in this metaphor also propagates a medical model of dementia that leaves little room for alternative responses - such as nonmedical and other psychosocial approaches - which enable people to routinely manage and live well with dementia (Kamphof, 2015: 366). Moreover, Lane, McLachlan and Philip (2013) question the appropriateness of militaristic metaphors in relation to dementia, given that there is currently no curative treatment (or "arsenal") with which the syndrome might be "fought". Following Sontag (1978), Lane and colleagues also question the usefulness of militaristic metaphors for people living with dementia, who might feel unable to "fight", and so be rendered 'battle-weary' by such tropes (2013: 281). Indeed, that millions of pounds of public funding have already been committed to (so far, unsuccessfully) developing a pharmacological solution to dementia gives cause to question whether at least a portion of that money would be better spent on non-medical interventions that focus instead on helping people with dementia and their families to live well with the syndrome.

\section{Representing people with dementia: heads and hands}

If dementia qua disease is represented as a dynamic entity (capable, for example, of wilfully 'killing'), then conversely people with dementia are constructed as passive and helpless 'victims'. In Hevey's (1992: 367) memorable phrase, they are 'done to' - a depiction in line with the 'master narrative' of dementia which construes living with the syndrome exclusively in terms of 'loss', 'failure', and 'meaningless existence'" (Harris and Keady, 2008: 7). Such de-humanising representations are realised both visually and linguistically, with the two modes combining to reinforce certain beliefs, attitudes and assumptions with respect to living with dementia, though the semiotic burden of realising these ideological values is almost exclusively carried by certain kinds of photographic images which recur with striking predictability across the news reports.

All the news stories we examined feature photographs of people purportedly (i.e. whom we are meant to take as) living with dementia. As with the aforementioned image of David Cameron, these pictures are not taken by press photographers attached to individual newspapers, but are culled from collections of stock images produced by picture agencies, and are thus instinct with values and assumptions (Machin, 2004) that do not have any essential relation to dementia and to the original 2016 Office for National Statistics report. Employing models and actors rather than actual people with dementia, they are fictional depictions and hence their value as artefacts coming close to 'the 'truth' of dementia experiences' has to be questioned (Swinnen, 2015: 72). ${ }^{2}$ Indeed, in many of these stock images it is not at all clear who the people appearing in them actually are. If, presumably, we are to take them as people with dementia, then they are merely generic figures or types who, as it were, perform dementia, performances based no doubt on what the image producers concerned stereotypically assume to be the patently recognisable reality of dementia, to wit, affliction and distress. We know and learn very little, if anything, about the participants other than that they are people with and suffering from dementia. These participants are always anonymous, are never named. They are 'de-storied individuals' (Eakin, 2004), individuals without any evident personal history, who never articulate their own story, whose voices we never hear. 
David Levi Srauss (2003: 26) argues that one of the key functions of any news photograph is to engender in its viewers 'feelings of distance and superiority'. Stock photographs of people with dementia appear to be no exception. Viewing the press's grim galère of dementiathemed images, we are hardly encouraged to respond to any of the participants in anything but a curious, quizzical and pitying way. The symbolic distance that opens up between viewers (us) and subjects (them) is brought about by a range of motivated semiotic choices (Hodge and Kress, 1988), not least the various newspapers' decisions to select images in which the participants (as people with dementia) avert their gaze away from that of the viewer and adopt certain postures and expressions. In these 'offer' images (Kress and van Leeuwen, 2006), the absence of eye contact makes it difficult to enter into any kind of symbolic relationship - at least one of social affinity - with the participants. They appear impersonally, objectified, as though they were, to quote Kress and van Leeuwen (2006: 119), 'specimens in a display case'. Consider, for example, figures 2 and 3, which illustrate this objectifying type of representation.

Figure 2. Image of man with dementia with (presumably) his son (Express)

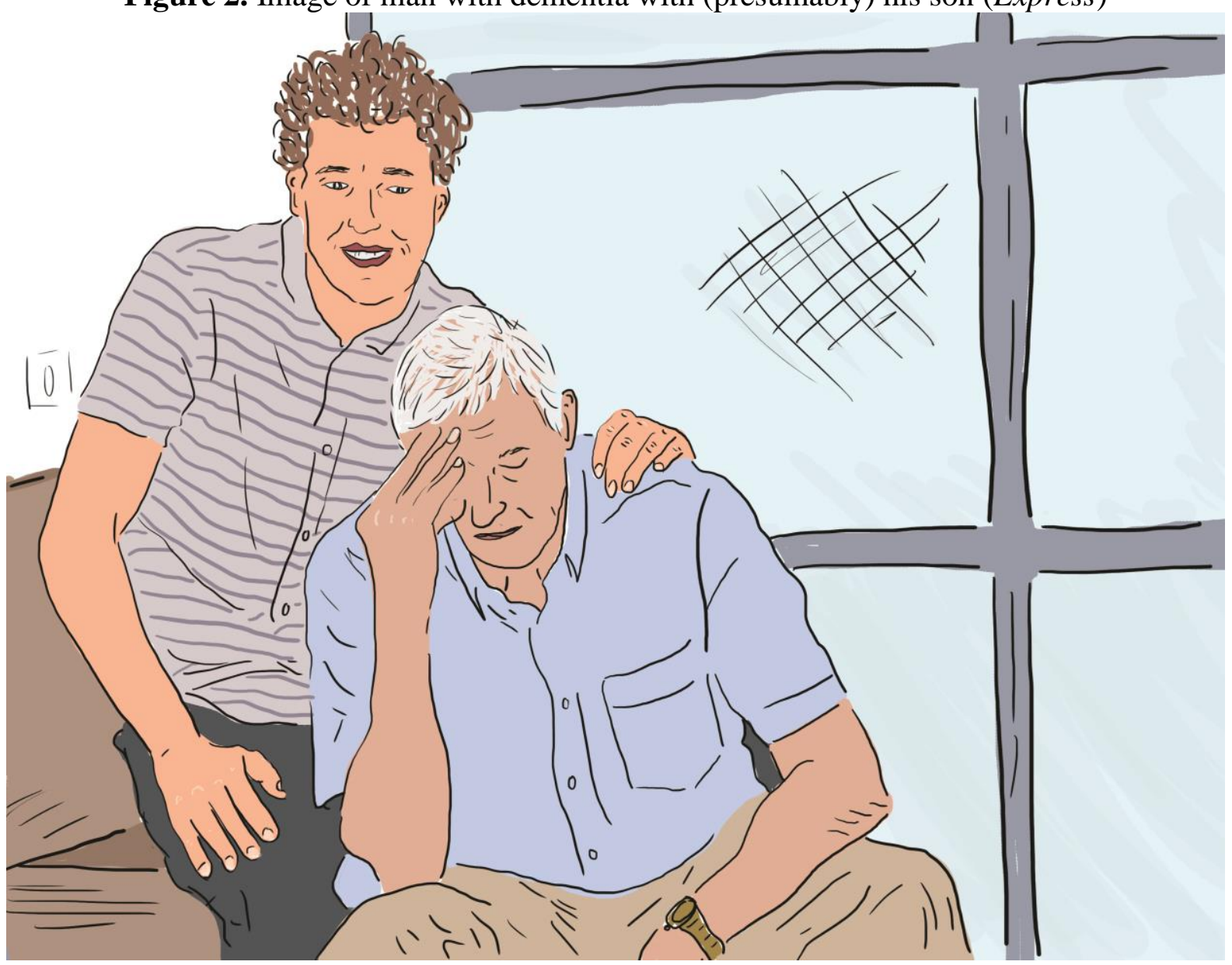


Figure 3. Image of woman with dementia with (presumably) her husband (Metro)

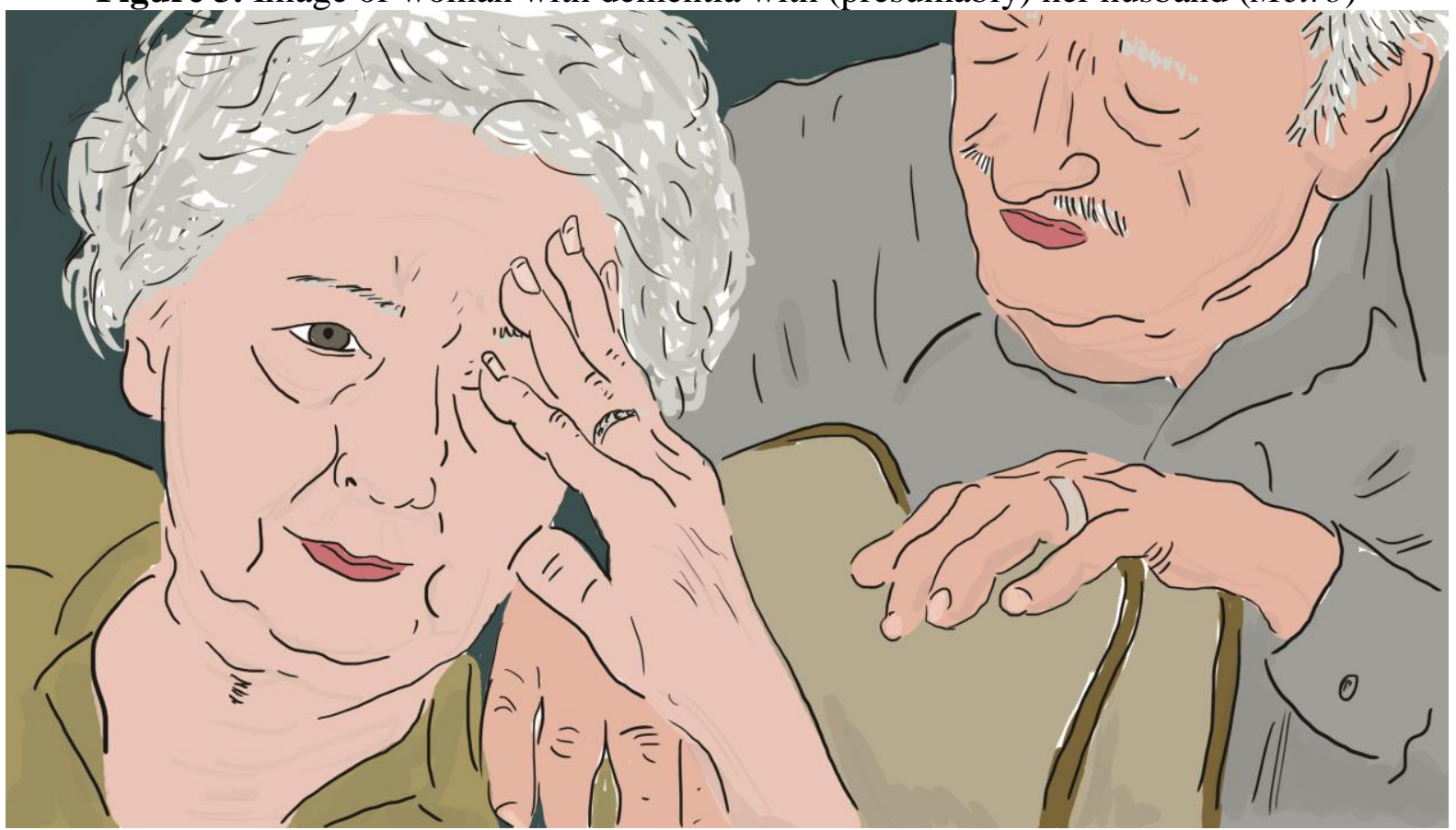

If there was any doubt that the foregrounded (proximally closest) participants in figures 2 and 3 are to be viewed as people with dementia, the captions which accompany these images in the press reports - 'Signs and symptoms of Alzheimer's' (Express) and 'Dementia is more common in women' (Metro) - dispel it. Although originating in different newspapers, these two images are strikingly similar in composition, both evidently designed to show people suffering from, rather than managing with, dementia. In the context of these images (and others like them), suffering is an appropriate choice of term here, since the participants, no matter how artificially staged the photographs in which they appear, are depicted in a somewhat abject and stricken state - docile bodies offered up for pitying scrutiny. They adopt passive poses - seated, immobile, vacant, pained - while their gazes are correspondingly downcast, appearing to look nowhere in particular and without object (quite in contrast to the purposeful gazes of the - presumably cognitively 'intact' - family members who comfort them, their gazes purposely fixed on their loved ones). The inertness of the dementia participants - not to mention their isolation, since even in the company and care of others they look disconsolately and inconsolably alone - is underscored by their position vis-à-vis their close companions - presumably a son in figure 2 and husband in figure 3 - who appear above them (if only slightly, but still symbolically, in figure 3) and are depicted in the act of a placing a comforting hand upon a shoulder, a gesture, however, which is neither reciprocated nor apparently apprehended.

But what, for us, stands out most significantly gesture-wise in this image is the way in which the two suffering subjects, as though in reaction to some pain or other inner disturbance, touch their brow with their fingertips, a visual detail which symbolically draws dementia to the surface for viewers to apprehend. ${ }^{3}$ In their classic sociological study of ageing, Featherstone and Hepworth (1993) observe how old age is characteristically perceived, metaphorically speaking, as a mask which hides the essential, enduringly uncompromised self beneath. According to this perspective, it is this visible mask of ageing (the wrinkles, grey hair and other markers emblematic of old age) that is 'pathological and deviant' rather than the inner self, which remains normal and healthy, even in the case of dementia. Quite 
crudely and somewhat brutally, the press images of dementia disrupt this common conception: in these depictions the true inner self of the person with dementia is evidently not an enduringly healthy but a diseased one, a spoiled self that, penetrating the ageing mask, is visibly revealed on the participants' faces. In reifying and localising dementia in this tangible way (note how the fingers in both images touch the same area of the forehead, as if dementia were precisely located there), the participants are thus distinctly marked with a stigma, an attribute of a person that is 'deeply discrediting' (Goffman, 1963: 13). Such an attribute, as Goffman acknowledges, is not inherently stigmatising in itself; it is more how it is perceived by others and by bearers themselves, but given the semiotic configuration of figures 2 and 3 , there is little doubt that viewers are directed to see the disease (or an aspect of its manifestation) before and perhaps instead of the person (Kitwood, 1997). Indeed these photographs reveal little of the character or psychological insight we might have otherwise gleaned from more nuanced and life-affirming images of people with dementia: certainly in no way do they contribute to the person-centred idea that people with dementia possess 'the same value as any other person' (Downs et al., 2006: 246).

In our press corpus of dementia photographs, the most common type of image by far is that of hands - specifically disembodied hands, images that subject participants to even greater levels of objectification (see figure 4). They are everywhere, these hands. They appear in all but two newspapers (Guardian and The Sun), recurring with predictable semiotic features and subtle but potent symbolic intent. The principal effect of these kinds of reductive visuals is to metonymically diminish the participants to little more than, in the words of WH Auden, 'anatomical data' (1976: 841). 
Figure 4. Examples of images of hands in the data

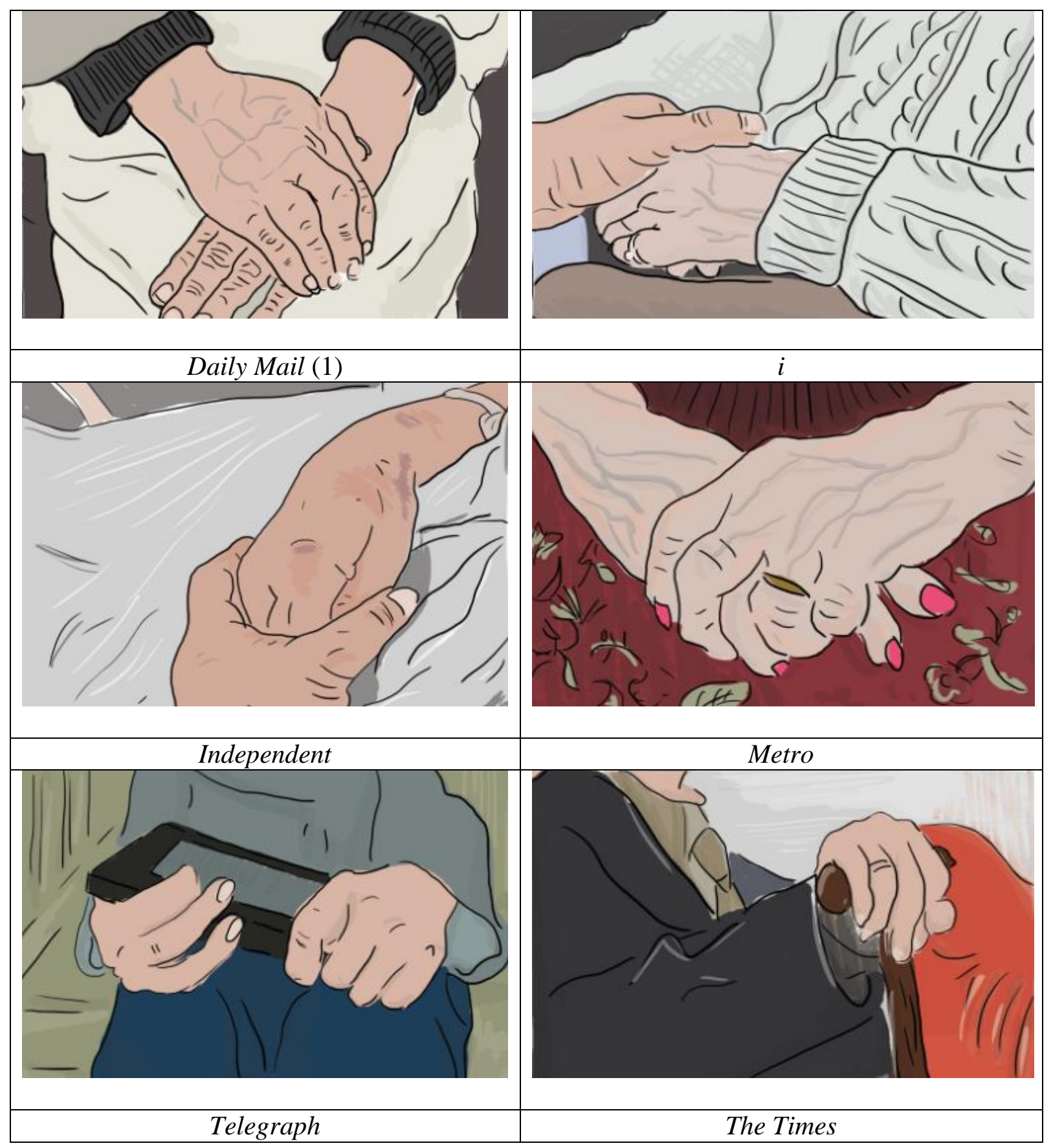

In figure 4 all the hands, which mainly appear in sharp focus against soft, blurred backgrounds, are tightly framed and rendered in extreme, emphasising close-up - or at least at such a close distance that other parts of the body, including, most significantly, the head (an absence to which we return shortly), are excluded from view entirely, and consequently we are denied any enlightening access to the individuals to whom these parts belong. The hands are always positioned centrally, prominently, looming out at the viewer. They are clearly, brightly lit - an intensity of illumination that reveals not only conspicuous features such as bruises and liver spots, but also creases and wrinkles in the skin and even the bones and joints beneath it. These are images of vulnerability. They emphasise fragility and deterioration. Take the Telegraph image, for instance. Note how the participant's right hand appears bereft of thumb and little finger, a visual act of 'enfreakment' (Hevey, 1992), with 
the hand taking on the disfiguring look of a talon or claw rather than the whole human organ, while in the Independent's image, the participant's hands are clasped together, the left hand holding the right, as if providing 'shelter' for it (Tallis, 2003: 118). As Tallis observes, clasped hands signify 'apprehension', a gesture which points to 'fears for the future' (119), and indeed one way of interpreting the position of the hands in this and other images in figure 4 is to see them as reacting to, and braced against, some evident (dementia-inflected?) hardship or state of suffering, albeit one left to viewers to intuit precisely for themselves. It is also intriguing to note that the participants in a number of these images clasp their own hands rather than someone else's - a gesture that emphasises loneliness and exclusion and, with this perhaps, the 'social death' that dementia is often said to entail (Sweeting and Gilhooly, 1997). Whatever the case, it is difficult to look at these hands, semiotically constructed as they are, without viewing them as 'evidence of the constraining body', emblems of otherness, isolation, and, even, reminders of mortality (Shakespeare, 1994: 292).

These and other media photographs of hands, then, not only index both old age and dementia, but their configuration also works to conceptually cement the two together. Indeed, in looking at these unremitting images of wizened, disembodied hands, one would be forgiven for thinking that dementia is an inevitable outcome of, or even, as Stuart-Hamilton (1994) puts it, a punishment for old age, leaving little scope for an alternative perspective of healthy or positive ageing. If, in actuality, dementia is not an inevitable consequence of the ageing process (Frölich, 2008), these images fail to communicate this reality or otherwise convey the sense that living with dementia can still involve having a life with dementia. Rather, they run the risk of perpetuating the idea, found in much of the medical literature (Kontos, 2006), that dementia is a 'loss of self' (Cohen and Eisdorfer, 2001), a disease that eradicates the wholeness and essence of the person.

The image of the spoiled and eroding self, in keeping with the press's dementia-as-biggestkiller master narrative, is further realised in a range of elaborate technical images. Figure 5, which appeared in the Metro, presents viewers with a digital illustration of a model head in flames, a visual metaphor that constructs dementia as a brain-engulfing conflagration. This striking, if profoundly distorting, pictorial trope involves a number of signifiers to represent the physical destruction that dementia 'wreaks' upon the brain, along with the damaged mind function that it leaves in its wake. Compact of sheets of loosely folded crumpled paper (eminently combustible material), the model brain appears to be burning easily and rapidly, the black ash it leaves in its wake visually suggesting the resultant cellular damage attributed to various forms of dementia. Intriguingly, however, this illustration of the flaming brain sits uneasily with certain sections of the written article of which it is part, for example: 'With dementia over time the brain becomes more damaged and doesn't work as well . . Dementia is a progressive disease meaning that symptoms worsen gradually over time' (our italics), descriptions that, in emphasising the slow progression of the syndrome, are misleadingly at odds with the corresponding visual construal of dementia as instant and all-consuming inferno. (In fact this is just one of several inconsistencies and misnomers: elsewhere in the article there is repeated mention of brain cell damage being caused by 'abnormal structures called "plagues". Presumably the journalist who researched and wrote the article meant 'plaques' rather than 'plagues', a no doubt inadvertent, but by no means inconsequential, solecism. $)^{4}$ 
Figure 5. Image of burning paper head with caption: 'Dementia is now said to be the leading cause of death in England and Wales' (Metro)

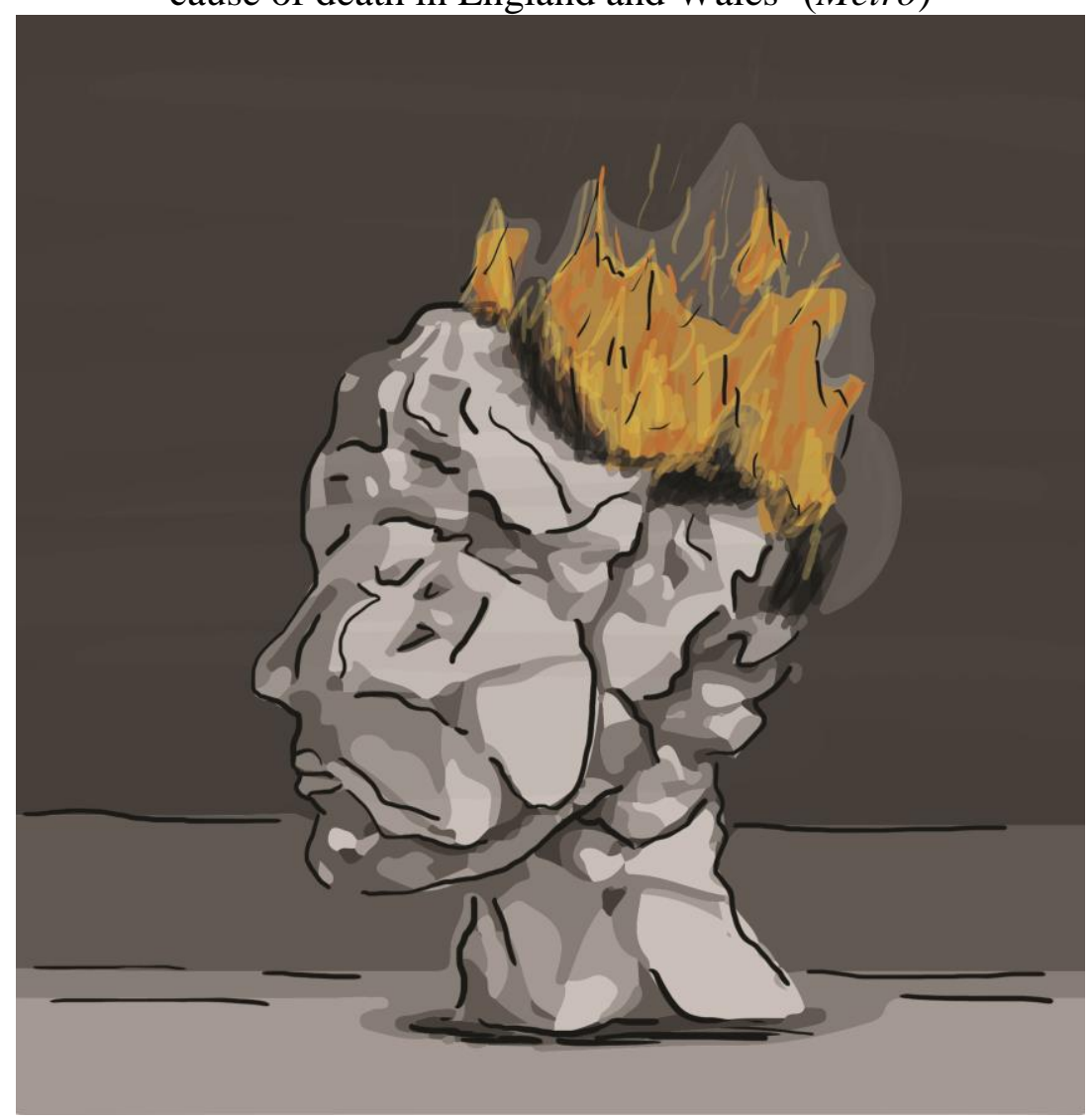

Of course, no matter how contradictory and misleading such visual images are, it is easy to appreciate how their concrete power is likely to appeal to journalists and editors trying to frame complex health-related news for public consumption, particularly a highly involved and often poorly understood socio-medical phenomenon such as dementia. ${ }^{5}$ Besides set-up photographs and digital illustrations, another type of recurring image harnessed by the media is the neuroimaging scan. As with photographic images of ageing and older people, which as Featherstone and Hepworth (1993: 306) argue, possess an 'immediacy and facticity which makes us think that they are real and self-evident', brain images are similarly chosen to give dementia stories 'more impact and encourage a particular reading' while closing down other ways of seeing things (Alvarado, 2001: 155).

Apart from their easy accessibility (they can be readily plucked from image banks), what makes brain scans particularly attractive to the press is that they are the most widely recognised icons of 'neuroscientific power today' (Pickersgill, 2013: 326), forming a class of so-called expert images which promise to tell us the evident truth (seeing is believing) about the state and function of the human mind (Dumit, 1999). But like photographs, which are often unquestioningly valued for their mimetic quality, brain scans also wield immense rhetorical and persuasive power and hence, as with other types of image, their deployment and representational uses need to be questioned (Machin, 2016). If, as Sontag (1977) argues, the camera makes the outside world around us 'atomic' and 'manageable', then neuroimaging renders 'the space enclosed by the skull' (Beaulieu 2002: 66) visible and articulable. Yet 
rather than take brain images for incontestable reality, a more cautious-critical approach would be to treat them as instances of 'manufactured objectivity', operating within the same aesthetic and technical conventions that shape the reception of other modes of popular scientific imagery (Burri and Dumit, 2008: 303). Consider, for example, figure 6, a computerised tomography (CT) scan which appeared in the Guardian and is one of a variety of neuroimaging pictures that featured in both tabloid (Express) and broadsheet (Guardian, Telegraph) newspapers.

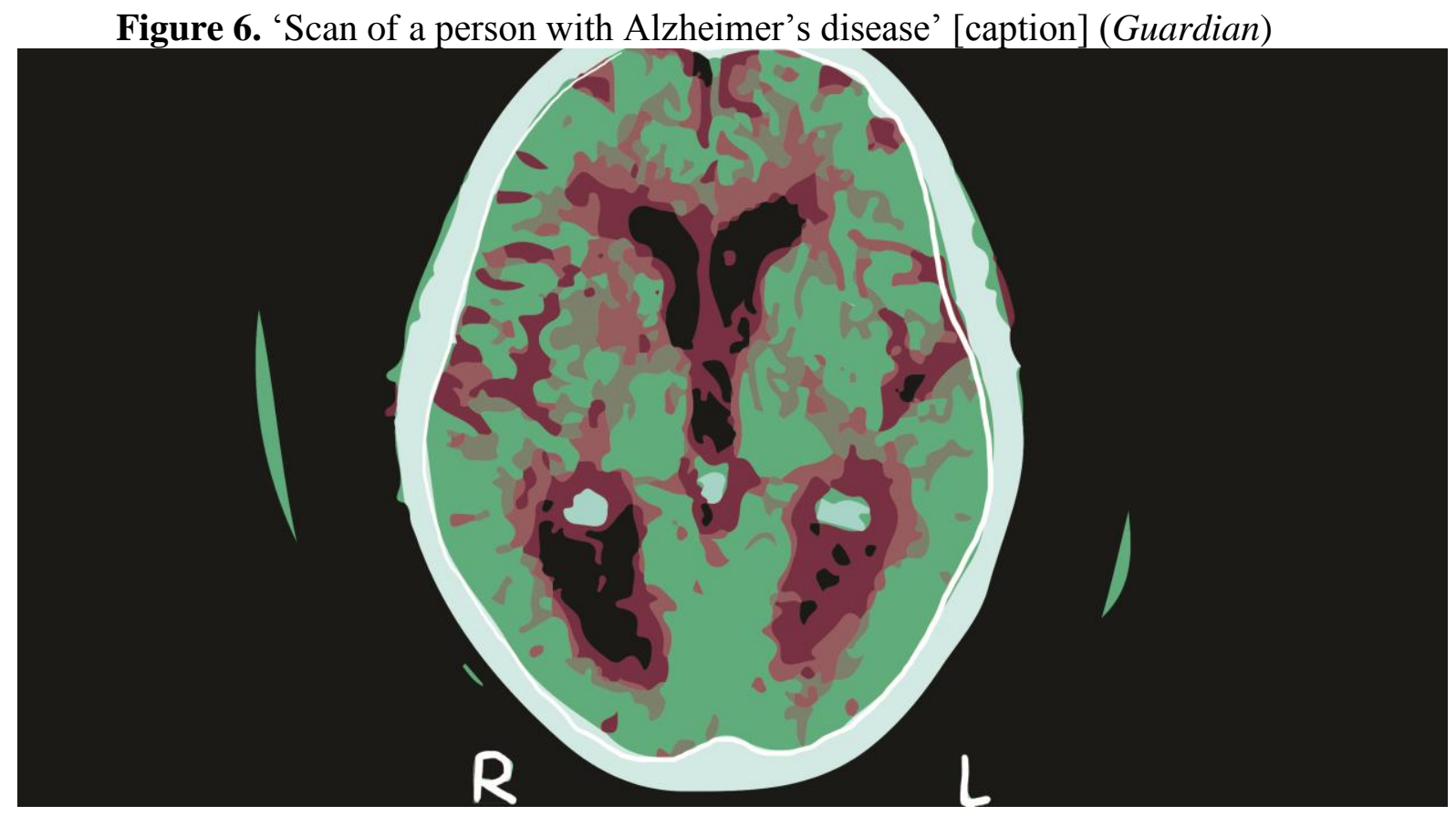

The CT scan of the brain here is at once instantly recognisable - iconic kind of image that it is (Taylor, 2014) - but also alien and unknowable. As the caption helps confirm, the image categorically presents us with Alzheimer's disease, the enlarged five dark ventricles (fluid filled spaces within the brain) appearing as visible biomarkers of the pathology. ${ }^{6}$ Very well. A seemingly useful heuristic. But what are (non-neuroscientific) viewers actually to make of this highly specialised technical image of the brain - or, more precisely, this cross-sectional slice of the brain which represents the whole brain, and in turn the person (Dumit, 2003: 44)? How exactly is this esoteric image supposed to aid their understanding or otherwise meaningfully illuminate the article which it visually headlines? The laconic caption hardly provides any useful direction on how to interpret the scan, which, consequently, is left to speak for itself - as though it could simply be read and understood like an everyday photograph. But, as Dumit observes, brain images are 'difficult to interpret precisely because they are not like photographs' (1999: 177 emphasis in original). Brain images require expert interpretation otherwise they run the risk of being apprehended as 'prejudiced and stylised representations of illness' (1999: 173). However, even if they don't understand them, few viewers, we suggest, are likely to question the functional veracity and authority of brain scans, not to mention their motivated inclusion by the press in the first place.

In some respects, then, the brain image in figure 6 is not unlike its figurative counterpart in figure 5 in that it allows us, albeit in an entirely different representational form, to see dementia in the brain. It is also an image that, appearing in the context of a press report, 
carries a large amount of rhetorical force. First, the scan persuades viewers of the tangible nature - the 'thinginess' - of dementia, no matter what the actual significance and consequence of the aforementioned swollen ventricles associated with Alzheimer's disease. As Moser argues (2008: 102), 'Imaging technologies and biological tests may give indications but do not prove nor disprove the presence of Alzheimer's disease'. Brain images, in other words, always possess a high degree of semiotic openness and are therefore subject to interpretation (Burri and Dumit, 2008: 306). But nowhere are readers made aware of the fact that such images are always polyvocal, that 'the inferences they suggest are by no means apodictic' (Fodor, 1999: 68). Nor, moreover, are readers informed that cellular change and damage in the brain is not necessarily a cause and consequence of dementia, and that a person bearing the cellular hallmarks of the syndrome will not always exhibit dementia symptomology (George et al., 2016). ${ }^{7}$

Another ideological consequence of reproducing neural images such as figure 6 (and others like it that have similarly been imported from a clinical into a lay context) is that they presuppose certain fixed categories of persons. Rendered in close organic and evidently transparent detail, there is 'something intuitively right' about this colourful, high resolution digital image and its ability to reveal essential differences between the pathological and healthy brain (Dumit, 2003: 37). Grappling with the neuro image, viewers, we suggest, would be led to assume that there are two kinds of brain (and by extension, two types of people): those with and those without dementia. Yet such an easy assumption would constitute a 'category mistake', that is, the assigning of qualities belonging to one category or thing to another category of a quite different kind: in this case the assumption that certain kinds of (diseased) brains mean certain kinds of (diseased) persons. Consequently, not only does the CT scan in figure 6 synecdochically reduce the person with dementia to their (aberrant) biology, but it also reinforces the difference between 'normal' people and people with dementia, further evincing a segregating 'us' and 'them' dichotomy. Whether intended or not, the reproduction of such technical brain imagery by the media does nothing to contradict the biomedical belief that 'everything a person with dementia does and feels is the outcome of brain damage and is abnormal in one way or another' (Sabat, 2014: 108).

\section{Concluding discussion}

In their perceptive study of the use of imagery in dementia campaign advertising, van Gorp et al. (2012: 389) offer the following observation: 'If one could speak about those with Alzheimer's disease with greater respect, people with Alzheimer's might also see themselves, and be perceived by others, as people in their own right and reintegrate into the social field.' In the collection of print media texts that we have examined in the present study, there was little evidence to indicate that the press were attuned to the significance of representing people with dementia sensitively and responsibly, tending, for the most part, to depict them in reductive, objectifying terms, as if to emphasise the popular misconception that dementia is always bigger than the person. Our semiotic analysis revealed how across all sections of the press - red tops, mid-market tabloids and broadsheets - people with dementia were variously constructed through discourses of loss and victimhood. Commonly reduced to body parts hands being the objectifying organ of choice - they were presented in disembodied form, devoid of mind, invoking perhaps the western philosophical tradition of treating mind and body as separate entities, with the mind being the humanising and rationalising principle, and the body a 'mere passive envelope' (van Gorp et al., 2012: 389). Apropos of dementia itself, the syndrome was discursively constructed as a violent and devastating entity, active and 
agentive, visiting death on large numbers of people or otherwise rendering them in a state of 'unbecoming' (Fontana and Smith, 1989), selves 'devoid of content' (Kontos, 2006).

Accordingly, in line with other studies that have critically examined dementia in the press, our research supports the contention that the media, which occupy a privileged position with respect to broadcasting dominant messages about health and illness, are not especially conscious of the long-term effect that they create in reproducing the same pernicious verbal and visual images of dementia. The effect and impact of recycling such fear-inducing and degenerative tropes, which seem just as much calculated to sensationalise as they do to inform, cannot be underestimated, for as Chivers (2011: 60) observes, the public are liable to associate 'dementia with the most horrifying possible loss of self', an assumption that is deeply embedded and continues to persist in western culture. This is not to claim that - in the case of press reporting - readers' responses to dementia are always uniform and offer no resistance to dominant media narratives about it. Yet it remains a fact that many people have a poor understanding of and continue to fear dementia more than they do other serious diseases, such as cancer, a view shared not only by older adults but also by young people (Alzheimer's Research UK, 2011).

While conducting our research, we often asked ourselves why the press, in line with much of its previous coverage of dementia-related stories (and not just epidemiological news items such as the Office for National Statistics story considered here), tended to focus on depicting the late stages of dementia at the expense of the early onset of the syndrome in which it is possible to 'learn to live with the disease before we reach what seems so frightening' (Whitehouse, 2008: 12), or why the press failed to harness more positive images that show the variability of persons with dementia (which is not, of course, a photographic impossibility: see, for example, Cathy Greenblat's (2011) life-affirming collection of images of people with Alzheimer's, images which allow viewers to read the disease against the prevailing dementia-as-unqualified-disaster grain). Naturally we are not so naïve as to assume that the media, as producers of mass mediated messages of health and illness, do not have a particular agenda that is likely to determine the content of their reports (Seale, 2003: 514). Positive stories, moreover, rarely meet (essentially) negative newsworthy criteria. Nevertheless, it is worth speculating a little further as to why the media is so uniquely consistent with respect to its reckless oversimplification of dementia and misrepresentation of people with the syndrome. Perhaps more than any other contemporary health concern, dementia, by dint of its sheer biological, medical, and cultural complexity, as well as its being a syndrome for which there are no effective treatments, let alone cures, has the greatest 'claim' for elaboration. Dementia, as Gubrium (1986: 67) reminds us, 'cannot be understood as a straightforward list of objective conditions'. The meaning of dementia, moreover, cannot be thoroughly and sensitively appreciated without broader reference to the intricate mix of 'social context, language and interaction' (Young et al., 2014: 62), a complex range of factors which, with its obligation to create stories quickly and communicate them as briefly and simply as possible, is beyond the careful consideration of the popular press. Compelled as it is to generate stories that are dramatic and unambiguous and in keeping with dominant and easily recognisable stereotypes that uphold popular expectations, the media is liable to manufacture meaning, to turn the inexplicability and uncertainty of dementia into a series of concrete images, allowing us to find meaning where it is fugitive or absent (Gray, 2004: 39). As Gray observes, the press 'cater for our need for order' (ibid.). In the absence of any simple explanations or cures, depicting dementia and people with dementia in simplifying and objectifying terms at least confers a measure of symbolic order on the syndrome, while simultaneously affording the public the illusion that they are seeing things plainly and clearly. 
Accordingly, faced with the media's unremittingly simplifying agenda, dementia scholars and those working with and advocating for people with dementia need, we suggest, to be alert to the ideological import of the textual and visual imagery ubiquitously employed by the press. This is especially the case with visual representations (photographs, scans, illustrations, and so on) of people with dementia, since, as Featherstone and Hepworth (1993: 304) point out, there is always 'the danger that viewers will mistake images for reality', taking them as 'concrete evidence of the actual relationships and activities that occur in everyday life.' To date there has been relatively little research that has critically examined visual depictions of dementia in the media. Enlightening as it is, research in the field tends to adopt content analysis-style approaches to media discourse which focus exclusively on the 'what-is-said' rather than the 'how-it-is-said', that is, the way in which content is rhetorically composed and buries meaning beneath its obvious, taken-for-granted surface (Fairclough, 1995). We are not arguing that our semiotic analysis is in any way unquestionably authoritative - that others examining the same media content will draw out the same meanings as we did. Nonetheless we hope to have offered sufficient semiotic evidence to support our claims and interpretations, and that, in doing so, we will have motivated others to pay close attention to the loaded text and imagery through which the press continues to reproduce dementia stereotypes, stigma and prejudice on a disturbingly routine basis.

\section{Notes}

1. It is worth noting here that 'nobody survives' a diagnosis of a whole host of other longterm conditions (e.g. diabetes, osteoarthritis) but, unlike dementia, they don't seem to generate quite the same kind of media hysteria.

2. Given the risk of people seeing through the images, it is hardly surprising that the text producers fail to make it clear to reader-viewers that the participants appearing in these set up photographs are actors rather than actual people with dementia, since that would, of course, spoil the illusion the press is trying to maintain, calling attention to the synthetic nature of its representations and hence compromising the dramatic impact of the dementia story.

3. At the same time, the gesture of head-holding also makes these participants appear as though they are experiencing a severe headache or migraine, although these complaints are not especially symptoms of dementia.

4. With respect to Alzheimer's Disease - although this doesn't apply to all types of dementia, all of which have their own unique aetiologies and manifestations - one of its hallmarks is the build-up of proteins in the brain that form structures known as 'plaques' and 'tangles'. The appearance and effect of these structures leads to the loss of connectivity between cells in the brain, 'and eventually to the death of nerve cells and loss of brain tissue' (Alzheimer's Society, 2014b).

5. Apart from their visual pungency, what also makes pictorial metaphors so vividly persuasive (perhaps more so than their textually realised counterparts) is that they permit the blending of target (dementia) and source domains (fire) into a 'single hybrid entity' (2008: 169). Such a visual conflation prevents text producers from having to spell out the metaphor 
(e.g. Dementia is Fire / Brain on Fire), where doing so, though still retaining its arresting potential, would most likely draw attention to the outlandish nature of the trope.

6. It is unlikely, we argue, that most readers would be able to identify the biomarkers of Alzheimer's disease in figure 6. What is 'abnormal' about the brain in this image is the enlargement of the five ventricles, the bottom two of which appear almost kidney-shaped. In a 'healthy' brain, the ventricles would appear more like slits. Ventricular enlargement is a consequence of loss of brain tissue, which is associated with dementia. Also the fluid filled spaces around the outside of the brain are more prominent, indicating that there is a degree of atrophy of the cerebral cortex (loss of brain tissue). This is more noticeable at the top and sides of the image (or, to put it more technically, the frontal and temporal lobes of the brain). How much of this readers would be able to ascertain for themselves is open to question.

7. Although neuroimaging is able to reveal cellular damage in the brain, as well as other hallmarks of dementia, it is still not a straightforward process, even during autopsy, to determine the extent of brain damage required for a diagnosis of dementia (Woods, 2011: 208). As Woods elaborates, 'some older people show dementia during life, with no obvious brain pathology at post-term, while others have significant pathology, but have been apparently unimpaired during life' (2011: 208). Despite the apparently incontrovertible evidence provided by neuroimaging, the line between the normal and pathological remains a fuzzy one (George et al., 2016: 23).

\section{Acknowledgement}

We would like to thank Krysia Ellis for providing the illustrations used in this article.

\section{References}

Alvarado, M. 2001. "Photographs and narrativity." In Representation \& Photography, edited by M. Alvarado, Buscombe, E and R.Collins, 148-163. London: Palgrave.

Alzheimer's Research Trust (2011) Alzheimer's Research UK launches as public dementia fears spiral <http://www.alzheimersresearchuk.org/Alzheimers-Research-UK launch/>. Accessed 28 Mar 2017.

Alzheimer's Society. 2014a. Demography [online]. URL: <https://www.alzheimers.org.uk/ info/20091/what_we_think/93/demography>. Accessed January 2017.

Alzheimer's Society. 2014b. What is Alzheimer's disease? [online]. URL: <https://www.alzheimers.org.uk/download/downloads/id/3379/what_is_alzheimers_ disease.pdf $>$. Accessed April 2017.

Alzheimer's Society. 2017. Factsheet 417: The later stages of dementia [online]. URL: < https://www.alzheimers.org.uk/site/scripts/download_info.php?downloadID=1100>. Accessed January 2017.

Annas, G. J. 1995. "Reframing the debate on health care reform by replacing our metaphors." The New England Journal of Medicine 332 (11): 744-747.

Auden, W. H. 1976. Collected Poems. New York: Random House.

Barthes, R. 1977. Image, Music, Text. New York: Hill and Wang.

Basting, A. D. 2009. Forget Memory: Creating Better Lives for People with Dementia. Baltimore: John Hopkins University Press. 
Beaulieu, A. 2002. "Images are not the (only) truth: Brain mapping, visual knowledge, and iconoclasm." Sci. Technol. Hum. Val. 27: 53-86.

Blume, L., N. A. Persily, and J. Mintzer. 1992. "The prevalence of dementia: The confusion of numbers." American Journal of Alzheimer's Disease \& Other Dementias 7 (3): 311.

Burri, R. and J. Dumit. 2008. "Social Studies of Scientific Imaging and Visualization." In The Handbook of Science and Technology Studies (third edition), edited by E. J. Hackett, O. Amsterdamska, M. Lynch and J. Wajcman, 297-317. Massachusetts: MIT Press.

Chivers, S. 2011. The silvering screen: Old age and disability in cinema. Toronto: University of Toronto Press.

Cohen, D. and C. Eisdorfer. 2001. The loss of self. London: W. W. Norton and Co.

Demmen, J., E. Semino, Z. Demjén, V. Koller, A. Hardie, P. Rayson, and S. Payne. 2015. "A computer-assisted study of the use of Violence metaphors for cancer and end of life by patients, family carers and health professionals." International Journal of Corpus Linguistics 20 (2): 205-231.

Doyle, C., D. Dunt, J. Pirkis, and B. Wijesundara. 2012. "Media reports on dementia: Quality and type of messages in Australian media." Australasian Journal on Ageing 31 (2): 96-101.

Downs, M., L. Clare, and J. Mackenzie. 2006. "Understandings of dementia: explanatory models and their implications for the person with dementia and therapeutic support." In Dementia: Mind, Meaning and the Person, edited by J. Hughes, S. Louw and S. Sabat, 235-258. New York, Oxford University Press,

Dumit, J. 1999. "Objective Brains, Prejudicial Images." Science in Context 12 (1): 173-201.

Dumit, J. 2003. "Is It Me or my Brain? Depression and Neuroscientific Facts." The Journal of Medical Humanities 24 (1): 35-48.

Eakin P. J. 2004. "What Are We Reading When We Read Autobiography?" Narrative 12 (2): 121-132.

Fairclough, N. 1995. Critical Discourse Analysis. Boston: Addison Wesley.

Featherstone, M., and M. Hepworth. 1993. "Images of ageing." In Ageing in Society: an introduction to social gerontology, edited by J. Bond, P. Coleman and S. Peace, 304332, London: Sage.

Fodor, J. 1999. "Diary.” London Review of Books, 21 (19): 68-69.

Fontana, A. and R. W. Smith. 1989. "Alzheimer's Disease Victims: The "Unbecoming" of Self and the Normalization of Competence." Sociological Perspectives 32 (1): 35-46.

Galtung, J. and M. Ruge. 1965. "The structure of foreign news: the presentation of the Congo, Cuba and Cyprus crises in four Norwegian newspapers." Journal of International Peace Research 1: 64-91.

George , R., E. Whitehouse, and P. Whitehouse. 2016. "Asking more of our metaphors: Narrative strategies to end the "war on Alzheimer's." The American Journal of Bioethics 16 (10): 22-24.

Goffman, E. 1963. Stigma. London: Penguin.

Gray, J. 2004. 'Icons of evil', New Statesman, 133 (4673): 38-39.

Greenblat, C. 2011. Love, loss, and Laughter: Seeing Alzheimer's differently. Connecticut: Lyons Press.

Gubrium, J. F. 1986. The Social Preservation of Mind: The Alzheimer's Disease Experience. Symbolic Interaction 9: 37-51.

Gwyn, R. 2002. Communicating Health and Illness. London: Sage.

Harris, P. B. and J. Keady. 2008. Wisdom, resilience and successful aging: Changing public discourses on living with dementia. Dementia 7 (1): 5-8. 
Herskovits, E. 1995. "Struggling over Subjectivity: Debates about the "Self" and Alzheimer's Disease." Medical Anthropology Quarterly 9 (2): 146-164.

Hevey, D. 1992. The Creatures Time Forgot: Photography and Disability Imagery. London and New York: Routledge.

Hughes, J. C. 2011. Thinking Through Dementia. Oxford: Oxford University Press.

Hodge, R. and G. Kress. 1988. Social Semiotics. New York: Cornell University Press.

Iedema, R. 2003. "Multimodality, resemiotization: extending the analysis of discourse as multi-semiotic practice." Visual Communication 2 (1): 29-57.

Jones, R. 2013. Health and Risk Communication: An Applied Linguistic Perspective. London and New York: Routledge.

Kamphof, D. J. 2015. "In the company of robots: Healthcare and the identity of people with dementia." Popularizing Dementia: Public Expressions and Representations of Forgetfulness, edited by A. Swinnen and M. Schweda, 359-376. Berlin: Mouton De Gruyter.

Kirkman, A. M. 2006. "Dementia in the news: the media coverage of Alzheimer's disease." Australasian Journal on Ageing 25 (2): 74-79.

Kitwood, T. 1997. Dementia Reconsidered: The Person Comes First. Maidenhead: Open University Press.

Kontos, P. 2006. "Embodied selfhood: An ethnographic exploration of Alzheimer's disease." Thinking about dementia: culture, loss, and the anthropology of senility, edited by L. Cohen and A. Leibing, 195-217. New Brunswick, NJ: Rutgers University Press.

Kress, G. and T. van Leeuwen. 1998. "Front pages: (The critical) analysis of newspaper layout." Approaches to Media Discourse, edited by A. Bell and P. Garrett, 186-219. Oxford: Blackwell.

Kress, G. and T. van Leeuwen. 2006. Reading Images: The Grammar of Visual Design. London and New York: Routledge.

Lane, H. P., S. McLachlan, and J. Philip. 2013. "The war against dementia: are we battle weary yet?" Age and Ageing 42 (3): 281-283.

Machin, D. 2004. "Building the World's Visual Language: The Increasing Global Importance of Image Banks in Corporate Media.” Visual Communication 3 (3): 316 -336 .

Machin, D. 2013. "What is multimodal critical discourse studies?" Critical Discourse Studies 10 (4): 347-355.

Machin, D. 2016. "The need for a social and affordance-driven multimodal critical discourse studies." Discourse \& Society 27 (3): 322-334.

Matthews, F., B. Stephan, L. Robinson, C. Jagger, L. Barnes, A. Arthur, and C. Brayne. 2016. Cognitive Function and Ageing Studies (CFAS) Collaboration: A two decade dementia incidence comparison from the Cognitive Function and Ageing Studies I and II. Nat. Commun. 7:11398.

Moser, I. 2008. "Making Alzheimer's disease matter. Enacting, interfering and doing politics of nature." Geoforum 39 (1): 98-110.

Nelkin, D. 1995. Selling Science: How the Press Covers Science and Technology. New York: W. H. Freeman.

NHS. 2011. Alzheimer's in the News: Fear and Fascination. Available from: http://www.thehealthwell.info/node/99638. Accessed: 20th March 2017.

ONS. 2016. Statistical bulletin:Deaths registered in England and Wales (Series DR): 2015 [online]. URL: <https://www.ons.gov.uk/peoplepopulationandcommunity/ birthsdeathsandmarriages/deaths/bulletins/deathsregisteredinenglandandwalesseriesdr/ 2015>. Accessed: January 2017. 
Peel, E. 2014. “"The living death of Alzheimer's' versus 'Take a walk to keep dementia at bay': representations of dementia in print media and carer discourse." Sociology of Health \& Illness 6 (6): 885-901.

Petty S., T. Dening, A. Griffiths, and D. M. Coleston. 2016. "Where is the happiness in dementia?" International Psychogeriatrics 28 (10): 1752-1753.

Pickersgill, M. 2013. "The social life of the brain: Neuroscience in society." Current Sociology. La Sociologie Contemporaine 61 (3): 322-340.

Potter, J., M. Wetherell, and A. Chitty. 1991. "Quantification Rhetoric - cancer on Television." Discourse \& Society 2 (3): 333-365.

Reah, D. 2002. The Language of Newspapers. London and New York: Routledge.

Richardson, J. E. 2007. Analysing Newspapers: An Approach from Critical Discourse Analysis. Basingstoke: Palgrave Macmillan.

Rundblad, G., P. A. Chilton, and P. R. Hunter. 2006. "An enquiry into scientific and media discourse in the MMR controversy: authority and factuality." Communication \& Medicine 3 (1): 69-80.

Sabat, S. R. 2014. "A Bio-Psycho-Social Approach to Dementia.” In Excellence in Dementia Care: Research into Practice (second edition), edited by M. Downs and B. Bowers, 107-121. New York: Open University Press/McGraw Hill.

Seale, C. 2002. Media and Health. London: Sage.

Seale, C. 2003. "Health and media: an overview." Sociology of Health \& Illness 25 (6) 513531.

Shakespeare, T. W. 1994. "Cultural representation of disabled people: dustbins for disavowal?" Disability and Society 9 (3): 283-299.

Sontag, S. 1977. On Photography. New York: Farrar, Straus and Giroux.

Sontag, S. 1978. Illness as Metaphor. New York: Farrar, Straus \& Giroux.

Starr, J. 2017. Dementia overtakes heart disease as the leading cause of death: But does this mean that incidence has increased? Maturitas 98: 51-52.

Stuart-Hamilton, I. 1994. The Psychology of Ageing: An Introduction (2nd edition). London: Jessica Kingsley Publishers.

Sweeting, H. and M. Gilhooly. 1997. Dementia and the phenomenon of social death. Sociology of Health \& Illness 19 (1): 93-117.

Swinnen, A. 2015. 'Ageing in film.' In Routledge Handbook of Cultural Gerontology, edited by J. Twigg and W. Martin, 69-76. London: Routledge.

Tallis, R. 2003. The Hand: A philosophical inquiry into human being. Edinburgh: Edinburgh University Press.

Taylor, K., 2012. The Brain Supremacy: Notes from the frontiers of neuroscience. OUP Oxford.

van Dijck, J. 2006. "Picturizing science: The science documentary as multimedia spectacle." International Journal of Cultural Studies 9 (1): 5-24.

van Gorp, B., and T. Vercruysse. 2012. "Frames and counter-frames giving meaning to dementia: a framing analysis of media content." Social Science \& Medicine 74 (8): 1274-1281.

van Gorp B., T. Vercruysse and J. van den Bulck. 2012. "Toward a more nuanced perception of Alzheimer's disease: designing and testing a campaign advertisement." American Journal of Alzheimer's Disease and other Dementias 27 (6): 388-396.

van Leeuwen, T. 2007. "Legitimation in discourse and communication." Discourse \& Communication 1 (1): 91-112.

van Leeuwen, T., and R. Wodak. 1999. "Legitimizing Immigration Control: A discourse historical analysis." Discourse Studies 1 (1): 83-119. 
Whitehouse, P. J. 2008. The Myth of Alzheimer's: What You Aren't Being Told about Today's Most Dreaded Diagnosis. New York: St. Martin's Griffin.

WHO. 2016. Dementia: fact sheet [online]. URL: <http://www.who.int/mediacentre/ factsheets/fs362/en/>. Accessed January 2017.

Woods, B. 2011. "The psychology of atypical ageing." In An Introduction to Gerontology, edited by I. Stuart-Hamilton, 192-225. Cambridge: Cambridge University Press.

Young, A., Ferguson-Coleman, E. and Keady, J., 2014. Understanding the personhood of Deaf people with dementia: Methodological issues. Journal of aging studies 31: 62-69.

Zeilig, H. 2014. "Dementia as a cultural metaphor." Gerontologist 54 (2):258-267.

Zeilig, H. 2015. "What do we mean when we talk about dementia? Exploring cultural representations of "dementia." Working with Older People 19 (1): 12-20. 